\title{
EXPERIMENTAL RESEARCH OF PAPERBOARD CUTTING IN DIE CUTTING PRESS WITH THE SCREW-NUT TRANSMISSION OF DRIVE MECHANISM OF A MOVABLE PRESSURE PLATE
}

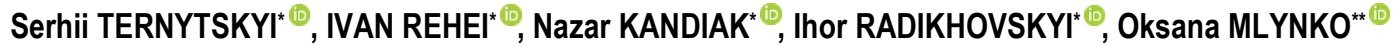 \\ *Faculty of Computer Printing Engineering, Department of Computerized Complexes of Printing and Packaging Industries, \\ Ukrainian Academy of Printing, Lviv, 79020, Pid Goloskom street, 19, Ukraine. \\ ${ }^{* *}$ Institute of Applied Mathematics and Fundamental Sciences, Department of Mathematics, Lviv Polytechnic National University, \\ Lviv, 79013, Bandera street, 12, Ukraine.
}

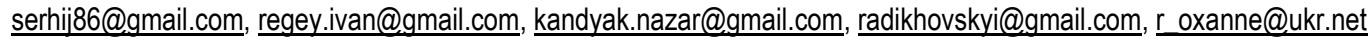

received 14 February 2021, revised 22 June 2021, accepted 25 June 2021

\begin{abstract}
This paper reports experimental research of torques during paperboard cutting in the die cutting press with the screw-nut transmission in the drive mechanism of the movable pressure plate. The purpose of the study is to substantiate the practical implementation of the pressure plate drive mechanism with the use of screw-nut transmission for the production of cartons of paperboard blanks. The manufactured experimental bench for the research of paperboard blanks provides the possibility of getting dependencies of loads on different parameters of the die cutting process. The developed method of the experimental research envisages the use of the strain gauge method and the wireless module for data measurement and software for its processing that allow getting trustworthy results with minimum faults. As a result of experimental research studies, the impact of paperboard thickness and cutting velocity on torque values has been established. Results of experimental research allow getting trustworthy and systematised information about torque values depending on the thickness of the paperboard, the paperboard fibre direction and pressure plate displacement velocity. It is established that torque values on drive shaft during die cutting of paperboard blanks made of folding boxboard with thickness that lay in range of 0.3-0.7 mm. Experimental research studies show the impact of rotation speed of a drive shaft of the pressure plate drive mechanism on the torque value. The article shows the workability of the designed device with screw-nut transmission in the drive mechanism of a movable pressure plate.
\end{abstract}

Key words: die cutting press, pressure plate, screw-nut transmission, leadscrew, ball screw, cutting knife, die cutting forme, paperboard blank, torque

\section{INTRODUCTION}

Today, the growth of the global packaging industry can be observed. In 2012, as it has been deskribed by Emblem A. and Emblem H. (2012), it was valued at over $\$ 400$ billion, roughly consituting $36 \%$ of paper and paperboard, $34 \%$ plastics, $17 \%$ metals and $10 \%$ glass; the remainder being made up of materials such as wood and textiles. Today, the global packaging market value is approximately $\$ 860$ billion, of which paperboard packaging accounts for roughly a third. The packaging market will grow by $\$ 280$ billion during 2020-2024 according to World Packaging Organisation.

As it was proved by Kirwan (2013), the main features that made paper and paperboard a significant part of the total packaging market are raw material properties, principles of manufacture and environmental and waste management. Paper and paperboard packaging has good appearance and performance properties that allow using it in a wide range of packaging.

Paper is usually defined as the substrate, made from vegetable fibres, which has a grammage of $<250$ grams per square metre (gsm), and paperboard has a grammage of $250 \mathrm{gsm}$ or more. This definitive difference, however, is not widely used within the industry, with different countries using varying terminologies. In Germany, paperboard has a grammage of $150 \mathrm{gsm}$ or more.

The main method of manufacturing paperboard packaging is die cutting. Due to this method, cutting and creasing is carried out using a flat die for sheet-fed materials or a rotary die for reel-fed materials. According to the book of Emblem A. and Emblem $\mathrm{H}$. (2012), the use of a flat die cutting forme allows packaging and manufacturing paperboard of different sizes and shapes. The forme is made from plywood, with steel cutting knives and creasing rulers inserted into grooves that are cut using a laser. On both sides of cutting knives are placed special foam rubber pillows that remove paperboard sheets from blades of cutting knives. The cutting and creasing operation manufactures paperboard packaging cartons.

Manufacturing paperboard packaging requires the performance of some technological operations. As it has been established by Rehei (2011), the chain of technological operations is accomplished automatically at paperboard blank stops during its periodical transportation through sections of equipment. Modern die cutting equipment is built on a section principle. The most important section is the press, which accomplishes the technological operation of die cutting. In die cutting presses, for pressure plate drive, special lever mechanisms are used. Khvedchyn and 
Zelenyi (2014) have carried out the analysis of existing mechanism designs of pressure plate drive in die cutting equipment and equipment from other industries, which perform operations that require overcoming a significant technological load at the end of the movement of the executive link. As it has been noted by the authors, the work of such mechanisms bases on wedging effect, which provides sufficient effort value of the pressure plate with comparatively little loads on driving links. Building such mechanisms causes asymmetry of the right and left part of the pressure plate during the movement cycle. The symmetry of plate movement can be seen only at the final stage of its displacement when the work surface of the pressure plate becomes parallel to the surface of the base plate and begins die cutting of paperboard blanks. This asymmetry causes unevenness of load distribution and shows oscillations in the press, which reduces the quality of paperboard packaging and production efficiency. The analytical research of different mechanisms of pressure plate drive conducted by authors allows evaluation of the quality level of compliant mechanisms to set parameters. However, detailed kinematic and kinetostatic analysis of mechanisms has not been carried out. Such analysis is important because of the complicated build of mechanisms and needs to overcome significant technological loads.

In the paper by Kuznetsov et al. (2012), analytical research studies of flatbed die cutting press with the pressure plate drive are conducted, which are built on the wedging effect. Analytical research studies have proven the occurrence of unevenness in the pressure plate movement during the press cycle. Such unevenness of plate displacement negatively affects load dispersion of the drive during the kinematic cycle. It also causes occurrence of loads oscillating in the drive. The method proposed by authors to eliminate unevenness of plate displacement by the ratio of the movement of the component slider change does not allow full elimination of plate movement unevenness during the press cycle.

Lin W. et al. (2015) have carried out research studies of die cutting press with dual-elbow-bar mechanisms. The authors have proved design complexity of such mechanisms of the pressure plate drive. The pressure plate drive that is built by such schemes has ten links that makes the mechanism complicated during operation. The analysis made by authors has shown high values of inertia force of the pressure plate during its movement. It has a significant impact on the drive mechanism of the die cutting press and its kinematic precision. Moreover, the mechanism causes a decrease in press productivity. Also, when the peak acceleration is reached, a shock load will occur. In view of existing drawbacks, the authors have proposed an optimised mechanism for the pressure plate drive. The main aim of the proposed mechanism is the improvement of pressure plate movement characteristics with maximum simplicity. It was proposed to use a cam mechanism in the drive of the pressure plate. However, such a mechanism design is characterised by the complexity of drive cams manufactured that have two contacting profiles because of the requirement manufacturing high-accuracy drive cams. Besides, such drive cams occupy a significant part of the die cutting press. Shakhbazov et al. (2020) have proposed a new design of wedging cam mechanisms of the lower pressure plate drive in die cutting press. Authors have conducted theoretical computations of technological loads that arise during cutting and creasing of paperboard blanks and of the size of the driving force which arises in the proposed wedging cam mechanism. Despite some simplification of design, the mechanism remains complicated in set-up and exploitation. Furthermore, the authors have not conducted experimental research studies of the proposed mechanism. Presses that will be built by such schemes would have complication in set-up and exploitation.

Vlakh and Pasika (2016) have created a methodology for main shaft work optimisation of the die cutting machine in the press. This methodology allows increasing productivity and production quality of die cutting machines with a decrease in its power assumption. The authors have derived analytical dependencies that provide mechanisms of synthesis conduction. To avoid the oscillating movement of the pressure plate of the die cutting press, the authors have proposed the use of a dual-cranck four-bar linkage or coulisse mechanism for the drive of a dualelbow crank instead of a direct electric motor. This helps to avoid quality deterioration of paperboard cutouts and increase production quality. However, the use of additional mechanisms causes complication in the design and set-up process of the die cutting press.

Kuznetsov et al. (2017) have proposed the use of a combined lever mechanism for the drive of the movable pressure plate of the die cutting press. It was made with an aim to minimise the drawbacks of existing equipment. The proposed mechanism consists of two pairs of crank-slider contours: leading and executive. The use of this mechanism decreases the total load and peak of kinetic power consumption. Nonetheless, besides the significant advantages of the proposed mechanism, it has a quite complicated design, and its dimensions are equal to existing mechanisms of the pressure plate drive of die cutting presses.

It was proposed by Happonen et al. (2015) to use laser cutting technology for paper and paperboard cutting. Potential and possible challenges of laser cutting of paper and paperboard-based materials have been discussed. The research aims to study the possibilities of laser cutting of paper material in the application area of complex low-volume geometry cutting. The authors have analysed the expediency of laser cutting according to the technique, quality and its realisation. Pinćjer et al. (2020) have researched the various parameters of laser in the cutting of paper. The results of this research show the perspective of laser use in paper and paperboard cutting. Also, the authors discovered the impact of different parameters of paper and paperboard on cutting power. However, the negative aspects of the use of lasers must also be investigated experimentally, especially the part related to environmental protection and safety at work. Besides that, laser cutting does not provide the necessary productivity of equipment, due to its low speed. The possible increase of laser cutting speed will significantly impact the cost of the process. Such a method of manufacturing paperboard packaging cartons is innovative and progressive.

Behen et al. (2020) have proposed a new design of the pressure plate drive of the die cutting press with an aim to avoid unevenness and provide strictly parallel movement during the pressure plate displacement. It can be achieved by the use of a screw-nut transmission in the drive mechanism of the pressure plate. The authors have researched kinematic parameters of the movable pressure plate of the die cutting press. The results of analytical research studies have shown the possibility and perspectives of the proposed mechanism use and the necessity of further research studies of the mechanism, especially its power parameters.

The screw-nut transmissions in press drive are mostly used in other areas that are not related to the production of paperboard packages. In the paper by Durand et al. (2018), it has been researched that screw presses are used for metal element pro- 
cessing (forming presses). The authors have analysed the parameters of a screw press and proposed methods for determining the required rigidity of the press. The results of these research studies do not consider the properties of paperboard and its behaviour during cutting because of the focus on the formation of sheet metal products. However, the results of the research studies are interesting and can be used for calculation of the required rigidity of the die cutting press.

Zou et al. (2017) have investigated the impact of the screwnut joint stiffness on the vibration characteristics of a vertical ball screw feed system without counterweight in the entire vertical position range through the development of a variable coefficient lumped parameter model. The created model is integrated with the modeling of the screw-nut joint stiffness under the preload and the weight of the spindle system. The preload weight model is compared with the preloaded model and the rigid model in predicting the dynamic characteristics of the system. The paper by Liu et al. (2015) has shown the method for modeling meshing behaviour of the roller screw accurately and has analysed the numerically calculated data which were used to evaluate the meshing characteristics. According to the results, it is possible to reach high loads by changing the parameters of the roller screw.

Rehei et al. (2020) have conducted an evaluation of components of the consumed kinetic power in the pressure plate drive with screw-nut transmission. The authors have created analytical dependencies that provide the evaluation of components of the consumed kinetic power that is spent on overcoming technological resistance during paperboard die cutting. It also considers inertia loads from moving masses of pressure drive elements and rolling friction of screw-nut transmission. The created method of the evaluation of the consumed kinetic power allows designing the pressure plate drive of die cutting presses with an application of the offered mechanism.

Because of the analysis of references, it can be concluded that the use of the drive mechanism of the pressure plate with screw-nut transmission allows avoiding drawbacks of existing die cutting presses in the area of pressure plate movement unevenness during the kinematic cycle. To confirm the reliability of ana- lytical research studies and efficiency of the proposed mechanism of the pressure plate drive with the use of the screw-nut transmission, experimental research is necessary to be conducted. The aim of this research is the conduction of technological loads in the pressure plate drive and its dependence on several parameters that change during paperboard packaging production. Moreover, the experimental research makes it possible to study rational parameters of paperboard cartons in flatbed presses with the screw-nut transmission in the mechanism of the pressure plate drive during die cutting.

The purpose of the study is to substantiate the practical implementation of the pressure plate drive mechanism with the use of screw-nut transmission for the production of cartons of paperboard packaging.

To achieve the goal of the study, the following tasks during the experimental research need to be solved:

- to design and manufacture the experimental bench with the use of the screw-nut transmission in the combined mechanism of the movable pressure plate drive;

- to study parameters of die cutting that have a significant impact on the process;

- to develop the method of experimental research: the placement of measuring instruments and carrying out measurements of technological loads (torques) in the mechanism;

- to observe the impact of geometrical, kinematical and technological parameters on torques that arise on the input link of the drive mechanism of the pressure pate.

\section{MATERIAL AND METHODS}

For experimental research, the experimental bench which includes screw-nut transmission in the drive mechanism of the movable pressure plate had been designed and manufactured. This bench, showh in Fig. 1, provides strictly parallel displacement of the pressure plate during the working cycle of the press.

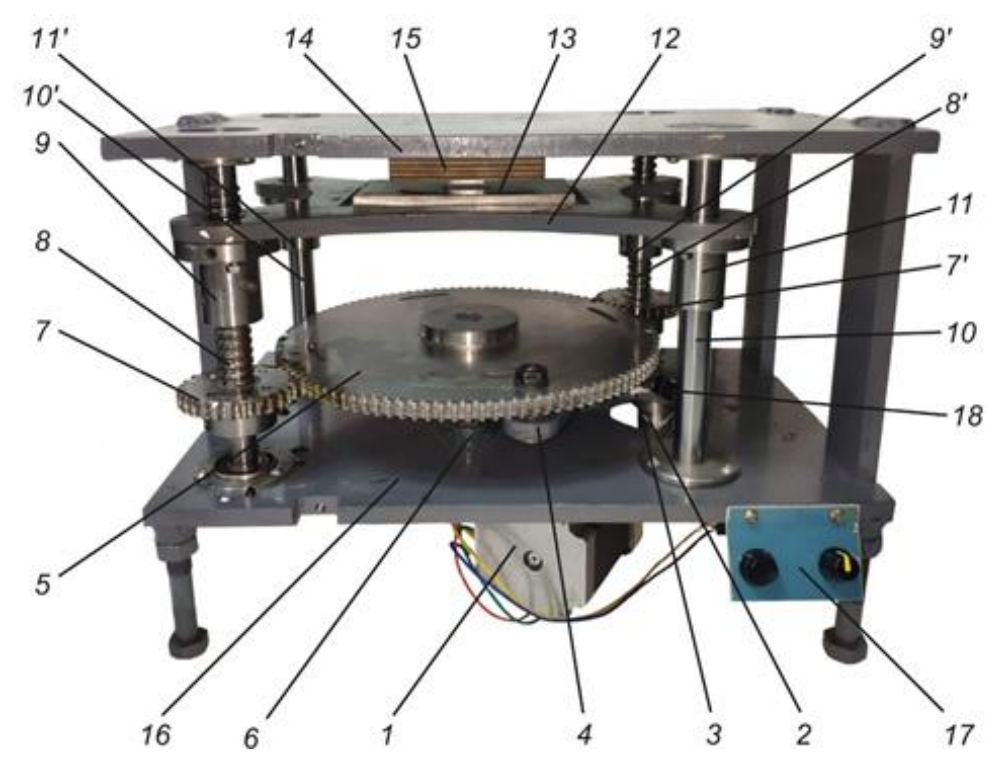

Fig. 1. Photo of the experimental bench for research on die cutting process with use of screw-nut transmission in the drive mechanism of the pressure plate: 1 - stepper motor, 2 - drive shaft, 3 - crank, 4 - connecting rod, 5 - gear wheel, 6 -thrust bearing, 7, 7' - gears, 8, 8' - vertical screws, 9, 9' -nuts, 10, 10' - cylindrical guides, 11,11' - linear displacement bearings, 12 - movable pressure plate, 13 - adjustment plate, 14 - base plate, 15 - die cutting forme, 16 - mount 
The experimental bench consists of a stepper motor 1 (Fig. 1) with a worm gearbox (not shown in figure), the connected drive shaft 2 of the experimental bench. On the drive shaft 2 is placed the crank 3 that is connected by a connecting rod 4 to a gear wheel 5 . The gear wheel 5 is placed on a vertical shaft and installed into thrust bearings 6 . The movement from the gear wheel 5 transfers to gears 7 and 7', which are fixed on vertical screws 8 and 8', respectively. On screws 8 and 8 ' are placed nuts 9 and ' ' ' of the ball screw, and the movable pressure plate 12 is fixed to it. In nuts 9 and 9', the motion of screws transforms into the reciprocating motion of the pressure plate 12 . To guarantee the strictly parallel movement of the pressure plate 12 , cylindrical guides 10 and 10' with linear displacement bearings 11 and 11', respectively, are used. On the movable pressure plate 12 is fixed an adjustment plate 13 on which the paperboard blank (not shown) is placed. The adjustment plate 13 additionally provides high-quality cutting of the blank. A base plate 14 with die cutting forme 15 is fixed to a mount 16 of the experimental bench. The mount 16 of the experimental bench has the necessary rigidity to ensure high-quality cutting of paperboard packaging cartons. The use of a stepper motor for the pressure plate drive allows smooth adjustment of kinematic parameters of the pressure plate movement and setting of a specific law of periodic motion in case of necessity.

For experimental research, the paperboard blank was placed on the adjustment plate 13 that is fixed to the movable pressure plate 12. The paperboard blank has the necessary parameters for experimental research. The hardness of the adjustment plate 13 was optimised for ensuring the cutting of the paperboard blank and minimising the blunt of the cutting knife edges. The die cutting forme 15 with cutting knives and a foam rubber is placed on the immovable base plate 14 that is fixed to bench mount 16 , which provides the necessary rigidity of the press. The pressure plate 12 performs reciprocating movement and brings the paperboard blank into the cutting zone. The experimental bench implements a flatbed scheme of a die cutting press design. The movable pressure plate 12 drive mechanism is carried out by the screwnut transmission where the pressure plate 12 is fixed to nuts 9 and 9'. Screws 8 and 8 ' are driven from gears 7 and 7' which are fixed onto it, respectively. Gears 7 and 7' are driven by a gear wheel 5 which is placed on a vertical shaft with the use of thrust bearings 6 . For the drive of the gear wheel 5 , a four-bar linkage is used. The drive shaft 2 is driven from the stepper motor 1 through the worm gearbox. On the drive shaft 2 is placed the crank 3 , and by the connecting rod 4 , the movement is transfering to the gear wheel 5 .

The experimental bench design shows the possible realisation of the pressure plate drive mechanism with the use of a screw-nut transmission with a leadscrew that provides the necessary displacement of the pressure plate. The use of such transmission has significant advantages: the possibility of obtaining a slow reciprocating motion of the pressure plate, providing relatively high power loads, high precision of plate displacement, design simplicity and small dimensions. To eliminate friction losses, a pair of screws and nuts and a ball screw which is characterized by low friction and fairly high efficiency (up to 0.9) are porposed to be used.. The ball screw consists of a screw and a nut with helical cut grooves of a curvilinear profile serving as tracks for balls. The modern ball screws can provide the necessary load for the operation of die cutting.

In the experimental bench design, two ball screws with a leadscrew are used. They are placed on the diagonal of the pressure plate and provide strictly parallel movement. To avoid the mismatch of the pressure plate during its movement, linear displacement bearings, which move along the vertically fixed cylindrical guides, are used. Such bearings make it possible to reduce the impact of friction forces during the pressure plate movement because of the low friction numbers.

The use of the worm gearbox with a gear ratio of 16 provides the desired speed range for the drive shaft of the drive mechanism of the pressure plate.

With the aim to get reliable load values that arise during die cutting of paperboard packaging by using the proposed drive mechanism of the pressure plate, a strain gauge method is used. This measurement method provides the needed precision of measurements. To measure torques in the researched mechanism on the drive shaft of the experimental bench, strain gauges are placed which change their resistance depending on values of loads according to recommendations of Schicher and Wegener (2002). When a conductor of the strain gauge is compressed such that it does not buckle, it will broaden and shorten, which decreases its end-to-end electrical resistance. From the measured electrical resistance of the strain gauge, the number of technological loads may be inferred. For reliable measurements of torques on the drive shaft of the mechanism, foil strain gauges N2A-06-T007R-350 with an electrical resistance of $350 \mathrm{Ohm}$ and a base of $100 \mathrm{~mm}$ are used.

As it is recommended by Hilal Muftah M. et al. (2013), strain gauges are glued on the drive shaft 1 (Fig. 2) of the experimental bench (a mechanism) at an angle of $45^{\circ}$ to the axis of the shaft and $90^{\circ}$ relative to each other.

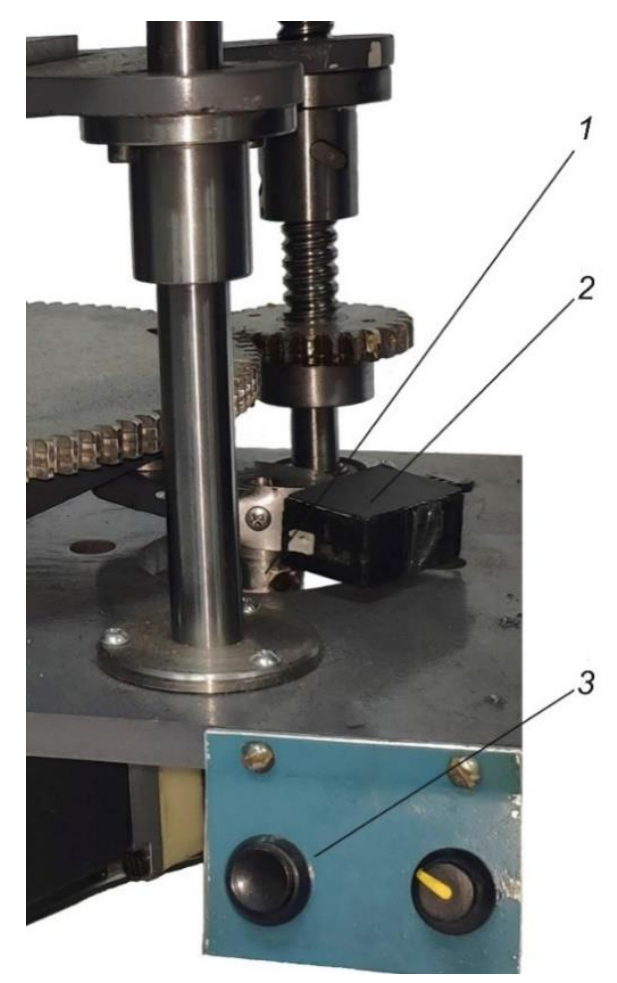

Fig. 2. Photo of strain gauge placement in the experimental bench: 1 - drive shaft, 2 - module of gathering, processing and transmission of the data, 3 - regulator

To prevent the influence of temperature fluctuations and reduce the influence of the bending of the drive shaft, four strain gauges are used for measurements, which are connected 
according to the complete bridge circuit. Power was supplied to one of the diagonals of the bridge circuit, and the output signal that shows the value of the load was obtained from strain gauges on the other diagonal of the bridge circuit. The connection of the strain gauge bridge to the measuring equipment was provided by a specially designed module 2 for processing and wireless data transmission. This kind of module, forgathering, processing and wireless data transmission was used to measure the tractive effort of the chain conveyor during spine processing of book blocks by Knysh et al. (2019).

The module for wireless data transmission consists of three elements: a 24-bit analogue-to-digit converter (ADC) Hx711 with an integrated amplifier (gain 128 times), microcontroller ATmega328P and Bluetooth HC05 module. The module provides gathering, processing and transmission of the data from strain gauges to future processing The microcontroller carries out the data processing from the ADC and its transfer by Universal Asynchronous Receiver-Transmitter (UART) protocol to the Bluetooth HCO5 module, which provides wireless data transmission. For the wireless data reception by Bluetooth v2.0 + Enhanced Data Rate (EDR) protocol from the module, software IVT Bluesoleil is used, which receives the data and creates a virtual communication (COM) port, where the data are transferred. To receive and display real-time results in a spreadsheet editor, MS Excel has been developed with macros in Visual Basic for Applications that read the data from the microcontroller through the virtual COM port, which decrypts and writes it to the appropriate cell spreadsheet editor without the use of an additional piece of software. The final processing and visualisation of the data are carried out by built-in functions of MS Excel.

To establish the compliance of $A D C$ data with the real torque values on the drive shaft of the drive mechanism of the pressure plate, the calibration of the measuring equipment has been done. For this purpose, the mechanism was stoped in one of the extreme positions; by measuring equipment with the needed value of load, the display of the ADC was fixed. The real values of torque on the drive shaft of the experimental bench are determined by known load values. However, during the calibration process, different loads have been used to convert the values of the ADC into the value of torque is used the dependence:

$\mathrm{T}=\left(\mathrm{n}-\mathrm{n}_{0}\right) \cdot \mathrm{K}$,

where $n_{0}-A D C$ starting value, $n-A D C$ current value, $\mathrm{K}-$ coefficient fo $A D C$ values conversion into the torque values that has been determined by dependence:

$\mathrm{K}=\frac{\mathrm{T}_{1}}{\mathrm{n}_{t}}$,

where $\mathrm{n}_{t}$ - the quantity of ADC values, that corresponds to the change of the applied load.

The experimental bench makes it possible to get torque values from cutting forces of paperboard blank. The design of the experimental bench provides displacement of the movable pressure plate for a distance of $80 \mathrm{~mm}$ by using geometric parameters of the gear and four-bar linkage mechanism. It used a ball screw and a lead screw of $5 \mathrm{~mm}$. Therefore, to ensure the movement of the pressure plate on the $80-\mathrm{mm}$ screws, it needs to make 1.6 turns, which is provided by the gear ratio between the gear wheel and gears. The gear wheel rotates by $100 \mathrm{deg}$. The use of a step motor for the experimental bench drive enables the smooth adjustment of the movement speed of the pressure plate by controlling the stepper motor with the designed regulator 3 (Fig. 2). This gives an opportunity to measure the torque value on the drive shaft of the bench with crank speed control depending on operation time. The beginning of the die cutting process starts with a sharp increase of the torque value.

For experimental research, the die cutting process with use of the proposed experimental bench was performed for the most common material - paperboard. According to Emblem A. and Emblem H. (2012) and Kirwan (2013), the most common paperboard for packaging is the folding boxboard (FBB), which has inner plies of a mechanical pulp and outer plies of a chemical pulp. This provides a board with maximum stiffness at minimum grammage. Such a type of paperboard provides the needed protective properties of packaging along with the possibility of obtaining high-quality printed packaging. For experimental research, paperboard blanks of a local manufacturer with a thickness of $0.3 \mathrm{~mm}$ (250 gsm), $0.45 \mathrm{~mm} \mathrm{(350} \mathrm{gsm),} 0.5 \mathrm{~mm}$ ( $370 \mathrm{gsm}), 0.6 \mathrm{~mm}$ (440 gsm) and $0.7 \mathrm{~mm}$ (500 gsm) were chosen. The thickness of paperboard blanks was measured and controlled during the experiments according to the recommendations of ISO 3034:2011. For experimental research, paperboard blanks have been conditioned at a temperature of $23^{\circ} \mathrm{C}$ and relative humidity of $50 \%$ for $4 \mathrm{~h}$.

The experimental research of torque on the drive shaft of the bench was conducted with the use of new cutting knives, made by Bohler, with the curvature radius with a cutting edge of $9 \mu \mathrm{m}$ and a thickness of $2 \mathrm{pt}(0.71 \mathrm{~mm})$.. According to the classification, the line-type Universal 40 with a length of $25 \mathrm{~mm}$ was used. Cutting knives have been selected according to existing recommendations.

\section{RESULTS OF EXPERIMENTAL RESEARCH}

The record of torque values on the drive shaft of the drive mechanism of the pressure plate that arises during paperboard cutting is shown in Fig. 3 and 4 . The abscissa shows the time equal to the division of the number of experimentally obtained values by the sampling frequency of the ADC. These diagrams have shown the results of torque value measurements during die cutting of the paperboard blanks with a width of $20 \mathrm{~mm}$ made of FBB and a thickness of $0.7 \mathrm{~mm}(500 \mathrm{gsm})$ in machine direction (MD) and cross direction (CD) at a rotation speed of $30 \mathrm{rpm}$.

Figs. 3 and 4 show two kinematic cycles of operation of the combined pressure plate drive mechanism of the die cutting press. The graphical dependencies can be conditionally divided into several segments. On segment A-G, the change of torque on the drive shaft of the mechanism is shown, which occurs during its operation without a paperboard blank and the cutting process. Segment G-N characterises the period of operation of the mechanism during the technological operation of paperboard blank cutting.

Comparing two kinematical cycles of the mechanism operation, it is seen that the operation of the mechanism is accompanied by the arise of significant inertial loads. Moreover, the gaps in the gearing, friction in the components of the combined mechanism, gaps in the kinematic pairs, the characteristics of the drive and the noise of electronic devices make a perceptible influence on torque value changes. 


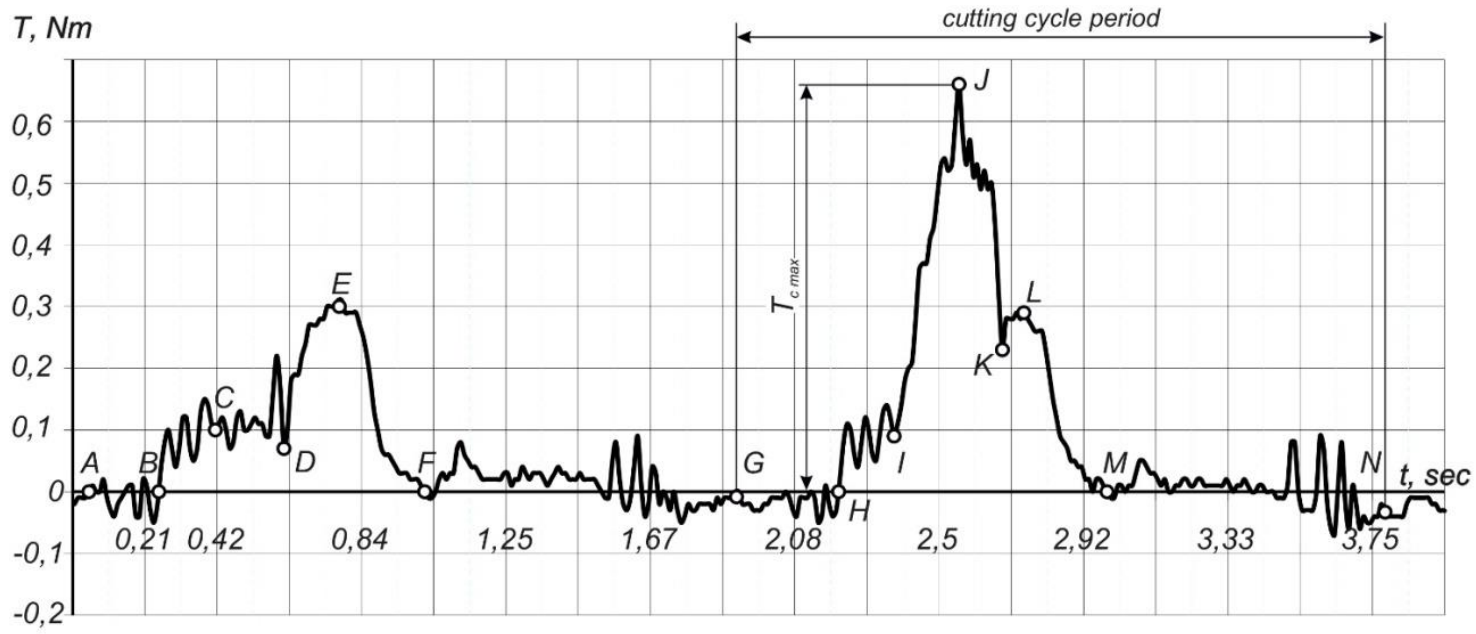

Fig. 3. Diagram of torque on the drive shaft of the drive mechanism of the pressure plate during die cutting of paperboard blank in MD and for paperboard FBB with a thickness of $0.7 \mathrm{~mm}$. FBB, folding boxboard; MD, machine direction

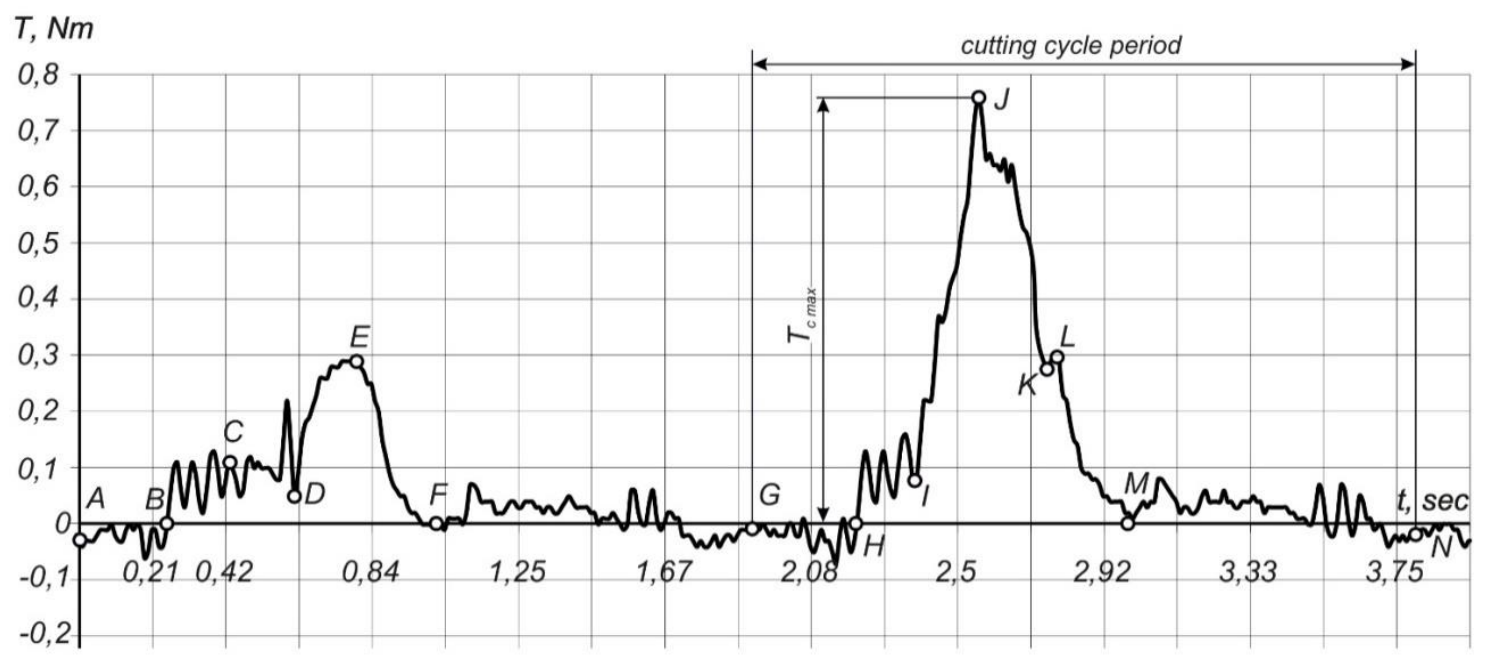

Fig. 4. Diagram of torque on the drive shaft of the drive mechanism of the pressure plate during die cutting of paperboard blank in $C D$ and for paperboard FBB with a thickness of $0.7 \mathrm{~mm}$. CD, cross direction; FBB, folding boxboard

At point $A$ begins a kinematical cycle of the drive mechanism of the pressure plate operation, and the torque value on the drive shaft starts to increase. At point $B$, the rubber foam of die cutting forme starts to contact the surface of the base plate, and the pressure plate continues to move. On segment $B-C$, the impact of gaps on the gear wheel and gears and the further increase of torque from inertia forces can be seen. At point $C$, the maximum value of torque from inertia forces reached maximum and begins to gradually decrease, which is caused by the feature of the fourbar linkage mechanism. Segment C-D shows the continuing increase of the torques from rubber foam deformation with a simultaneous reduction of the torque values from the inertia forces. At point $D$, the cutting knife touches the surface of the adjustment plate and can be seen as the rapid increase of the torque value till reaching the maximum value at point $E$. This torque increase characterises the load from the incision of the cutting knife into the surface of the adjustment plate placed on the immovable base plate. The incision of the cutting knife into the surface of the adjustment plate is a necessary condition for ensuring the reliable cutting of paperboard blanks. Then, the pressure plate changes the movement direction and begins to move away from the base plate that can be proof for the decrease in the level of torque on the segment $E-F$, reaching the minimum value at point $F$. On segment $F-G$, the drive mechanism of the pressure plate continues to return to the starting position. However, at this stage of the operation, the pressure plate moves downwards, and there is no significant load from the forces of inertia from components of the mechanism.

Then, the mechanism operation takes place in a logical sequence, but with the available paperboard blank, ie, the technological operation of cutting is carried out. The operation cycle of the drive mechanism of the pressure plate starts at point $G$ where the increase of torque values can be seen. Segment $G-$ $\mathrm{H}$ was characterised by slight changes in the torque value. At point $\mathrm{H}$, the rubber foam of die cutting forme begins to contact the paperboard blank, and on segment $\mathrm{H}-\mathrm{I}$, the increase of the torque value from the deformation forces of the rubber foam is observed. This segment, as in the previous case, shows the impact of gear gaps. At the point I, the cutting knife touches the paperboard blank and begins the incision of the cutting knife into the 
paperboard that is accompanied by the growth of the torque. The torque value increases to reach the maximum value which corresponds to point $\mathrm{J}$. This will be the torque value (Tc max) from the cutting of the paperboard blank. Next, there can be seen a sharp decrease of the torque value to reach some value at point $\mathrm{K}$. This sharp decrease of the torque value is since the particles of the paperboard blank are separated before the contact of the cutting line with the surface of the adjustment plate. At point $\mathrm{K}$, the cutting knife edge begins to contact with the surface of the adjustment plate that was accompanied by an increase in the torque value to reach the maximum at point $L$.

Then, the pressure plate of the experimental bench begins to move in the opposite direction, moving away from the base plate. The gradual decrease of the torque value from the deformation of the rubber foam is clearly visible in the area $L-M$. At point $M$, the contact of the rubber foam with the paperboard blank is completed. The further lowering of the pressure plate is accompanied by insignificant changes in the inertial loads (segment $\mathrm{M}-\mathrm{N}$ ).

During experimental research, it was found that the thickness of the cardboard blank does not impact the change character of the torque values, and for each paperboard thickness, there exists a certain torque value that arises during die cutting the blank. The significant impact on the torque amount has the placement of the cutting knife relatively to the directions of fibres in the paperboard blank.

During the experimental research, a certain data amount of torque values was obtained. Torque values are processed based on calibration dependencies in accordance with the experimental research program. With the aim to obtain valid results, the method of point estimation that consists of acceptance as the unknown true value of the distribution parameter has been used. Selective arithmetic mean (average) $x$ - the sum of random variable values that are got as a result of experimental sampling test divided by its volume:

$\bar{x}=\frac{1}{n}\left(x_{1}+x_{2}+\ldots+x_{n}\right)=\frac{1}{\mathrm{n}} \sum_{\mathrm{i}=1}^{\mathrm{n}} x_{i}$,

Gorvat et al. (2019), have considered methods of processing the experimental data according to mathematical statistics methods. In mathematical statistics, it has been proved that the selective arithmetic mean is the best (capable, irremovable and effective) estimate of the mathematical expectation of a random value. The selective arithmetic mean method obeys the normal law of distribution.

The processed experimentally obtained data of the average value of seven measurements (minimal and maximum values have been neglected) that eventually give the value of the torque values that arise during paperboard blank die cutting for selected paperboard examples, as shown in Tab. 1.

Tab. 1. Results of experimental research of torque on the drive shaft of the mechanism that arise during die cutting of paperboard blanks

\begin{tabular}{|c|c|c|c|c|c|c|c|}
\hline \multirow{2}{*}{\multicolumn{2}{|c|}{$\begin{array}{l}\text { Crank speed, rpm } \\
\text { Fibres direction }\end{array}$}} & \multicolumn{2}{|l|}{10} & \multicolumn{2}{|l|}{20} & \multicolumn{2}{|l|}{30} \\
\hline & & \multirow{2}{*}{$\begin{array}{c}\text { MD } \\
0.52\end{array}$} & \multirow{2}{*}{$\begin{array}{l}C D \\
0.58\end{array}$} & \multirow{2}{*}{$\begin{array}{c}\text { MD } \\
0.48\end{array}$} & \multirow{2}{*}{$\frac{C D}{0.56}$} & \multirow{2}{*}{$\begin{array}{l}\text { MD } \\
0,44\end{array}$} & \multirow{2}{*}{$\begin{array}{l}C D \\
0.52\end{array}$} \\
\hline \multirow{5}{*}{$\begin{array}{l}\text { Torque } \\
\text { values, } \mathrm{Nm}\end{array}$} & $\begin{array}{l}0.3 \mathrm{~mm}, \\
230 \mathrm{gsm}\end{array}$ & & & & & & \\
\hline & $\begin{array}{l}0.45 \mathrm{~mm} \text {, } \\
350 \mathrm{gsm}\end{array}$ & 0.67 & 0.73 & 0.61 & 0.7 & 0.6 & 0.54 \\
\hline & $\begin{array}{l}0.5 \mathrm{~mm}, \\
370 \mathrm{gsm}\end{array}$ & 0.72 & 0.79 & 0.62 & 0.66 & 0.59 & 0.6 \\
\hline & $\begin{array}{l}0.6 \mathrm{~mm}, \\
440 \mathrm{gsm}\end{array}$ & 0.81 & 0.85 & 0.77 & 0.79 & 0.68 & 0.72 \\
\hline & $\begin{array}{l}0.7 \mathrm{~mm}, \\
500 \mathrm{gsm}\end{array}$ & 0.79 & 0.96 & 0.76 & 0.82 & 0.67 & 0.71 \\
\hline
\end{tabular}

According to the values that are shown in Tab. 1, graphical dependencies of torque values that arise during die cutting of paperboard blanks in the experimental bench have been built. These dependencies are shown in Fig. 5. The analysis of diagrams allows revealing the dependence of torque size on the thickness of a paperboard blank and epy direction of a cutting knife placement relative to the direction of the paperboard fibres.

Analysing the graphical dependencies of the torque values on the drive shaft that arise during die cutting of paperboard blanks has been established that the thickness of the paperboard blank causes an increase in the value of torque. However, it should be noted that there is no direct proportional dependence of the torque value on the thickness of the paperboard blank. The increase of the paperboard blank thickness, from $0.3 \mathrm{~mm}$ to $0.7 \mathrm{~mm}$, causes the increase of the torque on the drive shaft of the experimental bench just in 1.52 time during paperboard cutting in MD (from $0.44 \mathrm{Nm}$ to $0.67 \mathrm{Nm}$ ) and 1.36 time during paperboard cutting in $\mathrm{CD}$ (from $0.52 \mathrm{Nm}$ to $0.71 \mathrm{Nm}$ ).

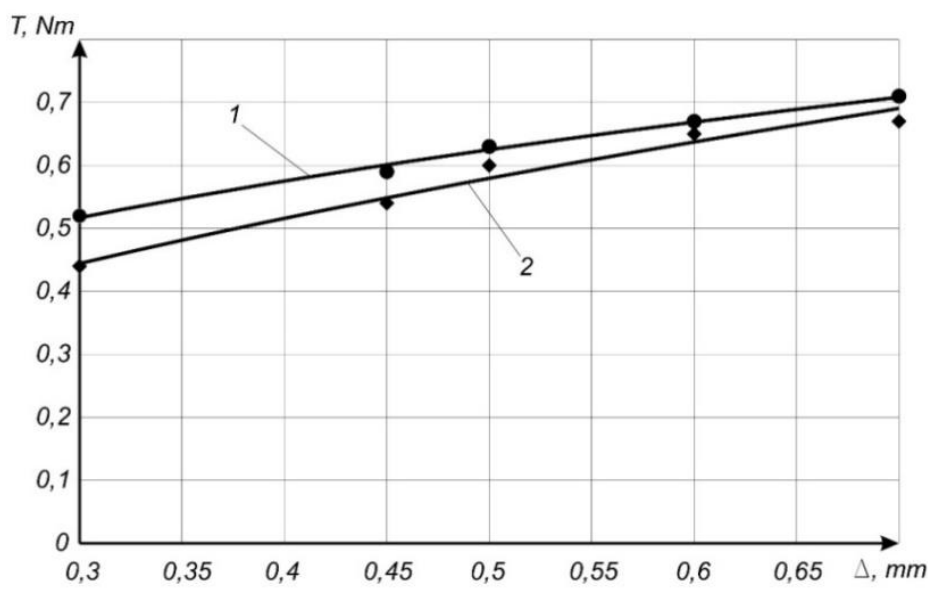

Fig. 5. Dependence of torque during die cutting on paperboard blank thickness measured on the drive shaft of the experimental bench: 1 - CD, 2 - MD. CD, cross direction; MD, machine direction 
As it is known, the direction of paperboard fibres relatively to cutting knife placement has an impact on the torque value. Experimental research has allowed us obtain paperboard cutting in $C D$; the value of torque on the drive shaft on the average is $7.5 \%$ higher than the cutting in MD (for paperboard, with a thickness of $0.3 \mathrm{~mm}$ and $0.7 \mathrm{~mm}, 15 \%$ and $5 \%$ is obtained, respectively).

The change of the torque on the drive shaft of the drive mechanism of the pressure plate depends on the paperboard thickness can be described by empirical dependencies of the type:

$\mathrm{T}_{\mathrm{c}}=\mathrm{A} \cdot \Delta^{\mathrm{n}}$,

where $\mathrm{A}\left(\mathrm{N} / \mathrm{mm}^{n+1}\right)$ and $\mathrm{n}$ are characteristics of a certain type of paperboard, which are obtained using the software as a mathematical description of the average line.

For the researched paperboard blanks made of folding boxboard with rotation speed of drive shaft of $30 \mathrm{rpm}$ :

- during paperboard cutting CD:

$\mathrm{T}_{\mathrm{c}}=0.83 \cdot \Delta^{0.52}$,

- during paperboard cutting MD:

$\mathrm{T}_{\mathrm{c}}=0.8 \cdot \Delta^{0.37}$.

The total dispersion $S^{2}$ (dispersion of the output parameter) characterises the scatter of the experimentally observed points relative to the average value. The closer the experimental data are to the diagram of empirical dependence, the closer the connection, the smaller the residual dispersion and the greater the correlation coefficient are. According to the results of experimental research studies, its processing and the development of the empiric dependence of the torque on the thickness of the paperboard with the dispersion value of 0.97 is due to paperboard cutting in MD and 0.99 during cutting in $C D$. Thus, a functional dependence was developed that describes the experimental values of the variables and accurately reflects the general trend of change of this dependence with the exception of measurement faults and random deviations.

The program of experimental research has provided the dependence of the torque value on the drive shaft of the experimental bench on its speed parameters. As previous, for experimental research, the same examples of the paperboard (FBB) blanks have been chosen. The conditions of the research remained unchanged except for the change in the speed of the drive shaft of the experimental bench $\left(n_{1}=10 \mathrm{rpm} ; n_{2}=20 \mathrm{rpm}\right.$; $\left.n_{3}=30 \mathrm{rpm}\right)$.

As it can be seen from the diagrams, the speed change of the experimental bench and therefore the cutting speed has little impact on the torque value. In the range of speeds that were studied (10-30 rpm), a decrease of the torque value on the drive shaft of the experimental bench while increasing its speed is observed. The triple increase of a rotation speed of the drive shaft and the crank of the bench cause the decrease of the torque value on the drive shaft on average by $15 \%$ during paperboard cutting in MD and by $20 \%$ during paperboard cutting in CD. For paperboard blanks with a thickness of $0.3 \mathrm{~mm}$, there is a decrease by $10 \%$ and for $0.45 \mathrm{~mm}, 0.5 \mathrm{~mm}$ and $0.7 \mathrm{~mm}$ there is a decrease by $25 \%$, and for blanks with a thickness of $0.6 \mathrm{~mm}$, there is a decrease by $15 \%$.

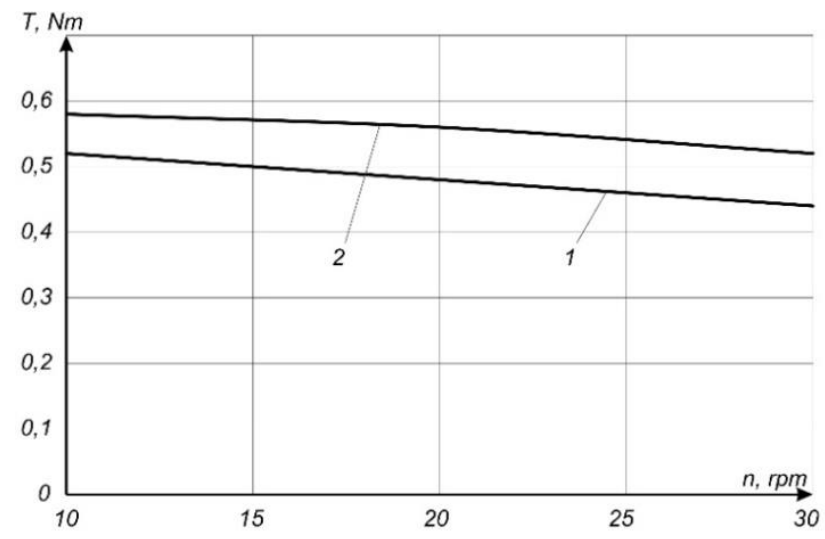

a)

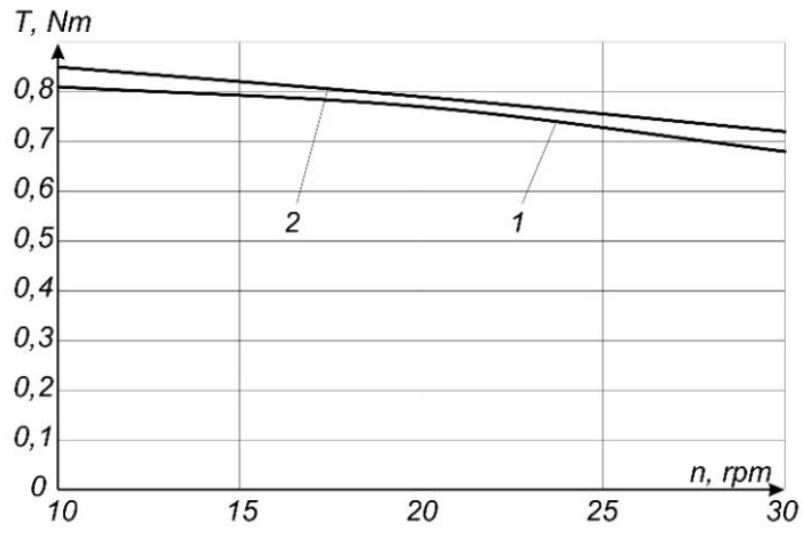

c)

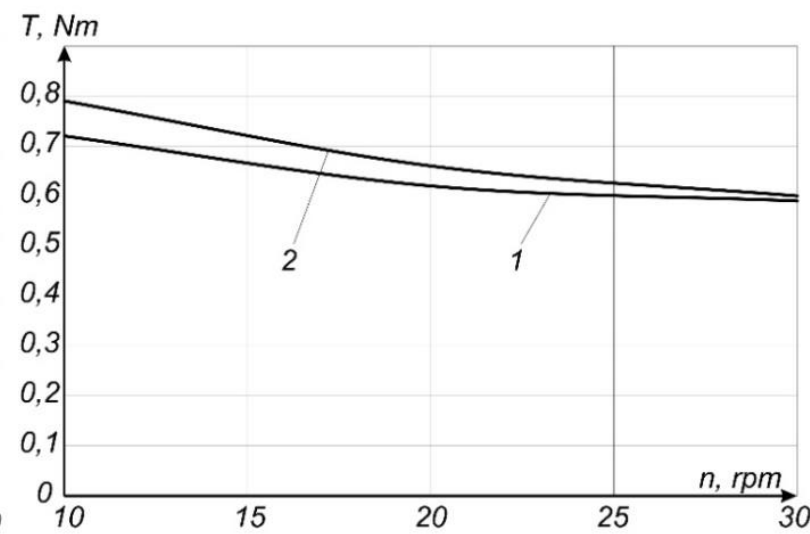

b)

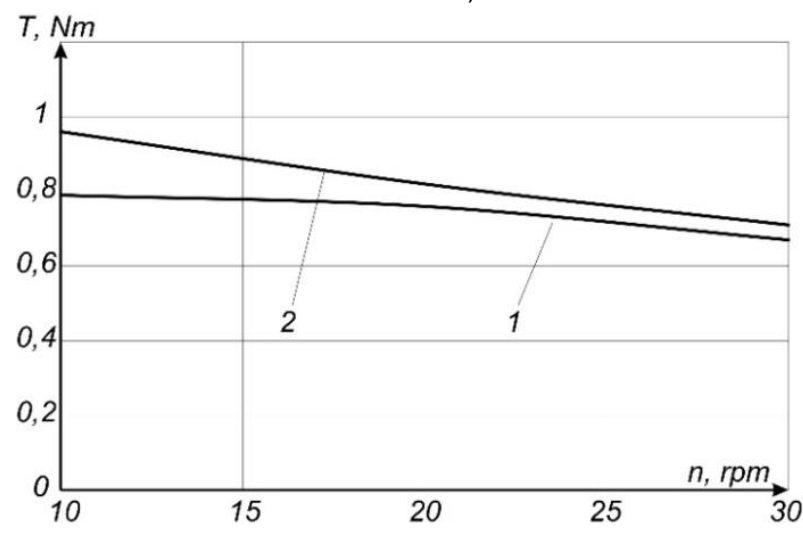

d)

Fig. 6. Dependence of die cutting torque on drive shaft of experimental bench on crank speed during paperboard cutting MD (1) and CD (2) for paperboard blanks made of FBB with thickness: $a-0.3 \mathrm{~mm}, b-0.5 \mathrm{~mm}, c-0.6 \mathrm{~mm}, \mathrm{~d}-0.7 \mathrm{~mm}$ 


\section{DISCUSSION}

From the obtained results when determining the influence of the thickness of the paperboard blanks on the torque values, the drive shaft of the experimental bench is logical and can be explained by an increase of the contact area of the cutting knife with the paperboard.. Also, fibres and their chemical connections influence torque. Increasing the paperboard thickness in diapason 0.3-0.7 mm causes the increase of the torque value, on average, 1.4 times. As for the force of paperboard cutting, it will vary in proportion to the embossing area, which will depend on the radius of curvature of the cutting edge of the cutting knife. The radius of curvature of the knife in the process of die cutting increases, which leads to a significant increase in force, which limits its suitability for further operation.

As it can be seen from Fig. 4, there is some difference between cutting in MD and CD of the paperboard blank. This pattern is due to the greater density in the $C D$ of paperboard. Paperboard is a material that consists mainly of intertwined and interconnected plant fibres containing cellulose. The thickness of plant fibres is $100-1,000$ times less than its length. Cellulose macromolecules in plant cells are placed parallel to each other forming fibrils, which are structural elements of cellulose fibre. Cutting a piece of paperboard in MD breaks the intermolecular bonds, which are much weaker than the bonds inside the cellulose fibre, and cutting in CD requires additional effort to break the fibre. This increase varies within $15-20 \%$.

Mathematical models of torque value dependence on paperboard thickness provides the possibility to get physical characteristics that correlate the stress and strain of paperboard. This can be made based on experimental diagrams of the processed functional dependence of torque value on the thickness of the paperboard blank. These dependencies are useful for determining the cutting force from the degree of blunting of the cutting knife using certain characteristics of the paperboard.

During experimental research studies, the impact of the speed on the crank of the experimental bench on torque value has been evaluated. The increase of rotation speed of drive shaft of the experimental bench causes the deacrese of torque. The tripple increase of rotation speed of drive shaft causes the decrease of torque on drive shaft in average by $15 \%$. It can be explained by the plastic deformation during paperboard cutting that depends on time of the operation.

It is important to note that the obtained results of the experimental research studies of the torques during die cutting of the paperboard blanks and the proposed method confirm the theoretical assumptions. It also should be noted that the research shows the workability of the proposed device. The use of screwnut transmission in the drive mechanism of the movable pressure plate of technological equipment for die cutting creates preconditions for high-quality manufacturing of paperboard packaging, simplifies equipment design and minimises power discharge.

\section{SUMMARY AND CONCLUSIONS}

The experimental bench with the screw-nut transmission in a combined drive mechanism of the pressure plate and a program of experimental research have been developed. The experimental bench allows a smooth change of the rotation speed of the drive shaft. The developed program of experimental research of torque values on the drive shaft provides detection of the impact of different die cutting processes and equipment parameters on the loads that arise during its operation. Proposed methods of measurements and obtained data processing with the use of modern hardware and software provide the processing simplification of the measurement results and make it possible to obtain reliable values with minimal faults.

Values of torque on the drive shaft of the drive mechanism of the pressure plate that arise during paperboard blanks of die cutting are established. Moreover, the impact of paperboard blank thickness on torque values is revealed.

It is established that the torque values on the drive shaft that arise during die cutting for thick paperboard blanks made of FBB lay in range of $0.3-0.7 \mathrm{~mm}$. It is found that the increase of the paperboard blank thickness from $0.3 \mathrm{~mm}$ to $0.7 \mathrm{~mm}$ causes the increase of torque on the drive shaft of drive mechanism of the pressure plate by 1.52 times during paperboard cutting in MD (from $0.44 \mathrm{Nm}$ to $0.67 \mathrm{Nm}$ ) and by 1.36 times during cutting paperboard in CD (from $0.52 \mathrm{Nm}$ to $0.71 \mathrm{Nm}$ ).

Mathematical models of torque value dependence on paperboard thickness are established. The total dispersion S2 is 0.97 during cutting in MD and 0.99 during cutting in $C D$; the paperboard shows the exception of measurement faults and random deviations.

The increase of rotation speed of the drive shaft of the drive mechanism of the pressure plate causes the deacrese of torque. The tripple increase of rotation speed of the drive shaft causes the decrease of torque on drive shaft in average by $15 \%$ during cutting in MD and by $20 \%$ during cutting in CD of the paperboard.

\section{REFERENCES}

1. Behen P. I., Radikhovskyi I. A., Mlynko O. I. (2020), Die-cutting Press wit Using a Lead Screw Transmission (Investigation of Pressure Plate Kinematic Parameters), Upakovka, 2020. № 1, 44-45 (in Ukrainian).

2. Durand C., Bigot R., Baudouin C. (2018), Contribution to characterization of metal forming machines: application to screw presses, Procedia Manufacturing, Volume 15, 1024-1032.

3. Emblem A., Emblem H. (2012), Packaging technology Fundamentals, Materials and Processes, Oxford: Woodhead Publishing.

4. Gorvat A. A., Molnar O. O., Minkovich V.V. (2019), Metodiobrobkieksperimentalnikhdanikh z vikoristannyam MS Excel. VidavnicztvoUzhNU «Goverla» (in Ukrainian)

5. Happonen, A., Stepanov A., Piili H., Salminen A. (2015), Innovation Study for Laser Cutting of Complex Geometries with Paper Materials, Physics Procedia, № 78, 128-137.

6. Hilal Muftah M., Mohamed Haris S., Petroczki K., AwadKhidir E. (2013) An Improved Strain Gauge-Based Dynamic Torque Measurement Method. International Journal of Circuits, Systems and Signal Processing, Issue 1, Volume 7, 66-73.

7. Khvedchyn YU. Y., Zelenyi V. V. (2014) Analysis of The Mechanisms of Press in Die-cutting Automat, Scientific Papers, № 4 (49), 21-30 (in Ukrainian).

8. Kirwan, M. J. (2013), Handbook of Paper and Paperboard Packaging Technology, Oxford: John Wiley \& Sons.

9. Knysh, O., Rehei, I., Kandiak, N., Ternytskyi, S. (2019), Experimental Evaluation of the Tractive Effort of the Chain Conveyor during Book Block Spine Processing by Cylindrical Milling Cutter at Perfect Binding, Acta Mechanica et Automatica, vol. 13 no. 2, 101-106.

10. Kuznetsov V. O., Kolomiets A. B., Dmitraschuk V. S. (2012), Parametric Researches of the Press Plate Drive in Die-cutting Automat, Upakovka, №6, 31-34 (in Ukrainian). 
11. Kuznetsov V. O., Rehei I. I., Vlakh V. V. (2017), Modification of a Drive Mechanism of a Press Plate in a Die-cutting, Press, Printing and Publishing, №1, 56-62 (in Ukrainian).

12. Lin W., Zhou C., Huang W. (2015), Optimum design for mechanical Structures and material Properties of the dual-elbow-bar mechanism, Hindawi Advances in Materials Science and Engineering.

13. Liu Y., Wang J., Cheng H., Sun Y. (2015), Kinematics Analysis of the Roller Screw Based on the Accuracy of Meshing Point Calculation, Mathematical Problems in Engineering, vol. 2015.

14. Pinćjer I., Miketić N., Tomić I., Adamović S. (2020). Exploring the Various Parameters of $\mathrm{CO} 2$ Laser in the Cutting of Paper. Paper presented at the 10th International Symposium on Graphic Engineeringand Design GRID 2020, Novi Sad, Serbia, November 12-14.

15. Rehei I.I., Knysh O. B., Behen P. I., Radikhovsky I. A., Mlynko 0. I. (2020). Drive of The Pressure Plate of the Die-cutting Press on The Basis of Using the Screw Nut Transmission (Method of Evaluation of Consumption Power Components), Scientific Papers 1 (60), 98-107 (in Ukrainian).

16. Rehei, I. (2011), Consumer Cardboard Packaging: Materials, Materials, Design, Manufacturing Equipment, Lviv: Ukrainian Academy of Printing (in Ukrainian).

17. Schicher R., Wegener G. (2002). Measuring Torque Correctly, Hottinger Baldwin MesstechnikGmbh, Germany.
18. Shakhbazov J., Cheterbukh O., Shyrokov V., Palamar O. (2020). The Drive Mechanism of a Pressure Plate of a Flat Die-cutting Press, Printing and Publishing, 1 (79),112-120(in Ukrainian).

19. Vlakh V., Pasika V. (2016), Automated Synthesis of Mechanism of Press of Diecutting Machine, Technological Complexes, №1 (13), 5763 (in Ukrainian).

20. Zou C., Zhang H., Lu D., Zhang J., Zhao W. (2017), Effect of the screw-nut joint stiffness on the position-dependent dynamics of a vertical ball screw feed system without counterweight, Proceedings of the Institution of Mechanical Engineers, Part C: Journal of Mechanical EngineeringScience. 232.

Serhii Ternytskyi: (iD https://orcid.org/0000-0002-3814-9762 Ivan Rehei: (iD https://orcid.org/0000-0002-3395-2994 Nazar Kandiak: (iD https://orcid.org/0000-0002-4720-3935 Ihor Radikhovskyi: (D) https://orcid.org/0000-0002-5036-3569 Oksana Mlynko: iD https://orcid.org/0000-0001-9878-6846 